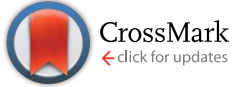

Cite this: RSC Adv., 2017, 7, 14389

Received 6th January 2017

Accepted 27th February 2017

DOI: $10.1039 / c 7 r a 00208 d$

rsc.li/rsc-advances

\section{Binuclear alkynylplatinum(II) terpyridine complexes with flexible bridges behave as organogelators for several organic solvents $\dagger$}

\author{
Ling-Bao Xing, ${ }^{* a b}$ Fei Qiao, ${ }^{b}$ Zhao Yuan, ${ }^{b}$ Jing-Li Zhang, ${ }^{b}$ Rui-Ying Zhang, ${ }^{\text {b }}$ \\ Shuping Zhuo ${ }^{\mathrm{b}}$ and Zi-Yan Zhou ${ }^{\mathrm{b}}$
}

\begin{abstract}
New binuclear alkynylplatinum(II) terpyridyl complexes with flexible bridges have been synthesized and characterized by ${ }^{1} \mathrm{H}$ NMR, mass spectra and elemental analysis. These compounds can gelate a variety of organic solvents via multiple intermolecular interactions such as metal-metal (Pt $\cdots \mathrm{Pt}$ ) and $\pi-\pi$ stacking interactions, hydrogen bonding interactions, and van der Waals forces, which were confirmed by ultraviolet-visible (UV-vis) absorption spectroscopy, rheological studies, temperature-dependent ${ }^{1} \mathrm{H}$ NMR spectroscopy, X-ray diffraction (XRD) and Fourier transform infrared (FT-IR) spectroscopy. Moreover, compound $1 \mathrm{~b}$ with a longer flexible bridge $\left(-\mathrm{O}_{(}\left(\mathrm{CH}_{2}\right)_{6} \mathrm{O}-\right)$ exhibited higher gelation ability than that of compound 1a with a shorter flexible bridge $\left(-\mathrm{O}\left(\mathrm{CH}_{2}\right)_{4} \mathrm{O}-\right)$. A scanning electron microscopy (SEM) investigation of the xerogels from different organic solvents gave a visual image showing that fibrillar aggregates are entangled in three-dimensional network structures.
\end{abstract}

\section{Introduction}

Low molecular weight gelators (LMWGs), which are organized by non-covalent interactions such as hydrogen bonding, $\pi-\pi$ interactions, van der Waals forces and dipole-dipole interactions, have shown promise for use in many fields, ${ }^{1-8}$ including molecular electronics, drug delivery, light harvesting and energy transfer and tissue engineering. Parallel to the growing interest in the development of organogels, there has also been an increasing interest in the investigation of transition-metal complexes as metallogelators, ${ }^{9-18}$ especially platinum(II) complexes. As a famous transition-metal complex, square-planar platinum(II) polypyridine complexes possess diverse excited states, high-emission quantum yields, and long triplet excited-state lifetimes, which have demonstrated promise for various potential applications, ${ }^{19-30}$ including photocatalysis, optical sensors, electron transfer, photochromism and so on. Especially, benefiting from intermolecular metal-metal (Pt $\cdots \mathrm{Pt})$ and $\pi-\pi$ stacking interactions, the complexes have a strong tendency to self-assemble into highly ordered linear chains or oligomeric structures. ${ }^{31-36}$

Yam and Ziessel's group firstly demonstrated that alkynylplatinum(II) terpyridyl complexes are capable of forming stable

${ }^{a}$ Key Laboratory of Colloid and Interface Chemistry, Key Laboratory of Special Aggregated Materials, Ministry of Education, Shandong University, Jinan 250100, China.E-mail: lbxing@sdut.edu.cn

${ }^{b}$ School of Chemical Engineering, Shandong University of Technology, Zibo 255049, P. R. China

$\dagger$ Electronic supplementary information (ESI) available. See DOI: $10.1039 / \mathrm{c} 7 \mathrm{ra00208d}$ metallogels and showed drastic color changes during the gel-tosol phase transition. ${ }^{37,38}$ Che and coworkers reported a dicationic platinum(II) terpyridyl complex which can form phosphorescent organogels in acetonitrile or in a mixture of acetonitrile and alcohol. ${ }^{39}$ Yam and coworkers developed a series of alkynylplatinum(II) complexes which were found to show strong luminescence enhancement upon a gel-to-sol phase transition upon increasing the temperature. ${ }^{40}$ De Cola and coworkers developed a straightforward strategy to obtain a new class of platinum(II) complex by using 2,6-bis(tetrazol-5yl)pyridine with particular photophysical properties owing to the formation of self-assembled gels. ${ }^{41,42} \mathrm{Tu}$ and coworkers established a method for the visual chiral recognition of $(R)$ and $(S)$-binap through an enantiocontrolled breakdown of gels prepared from novel aromatic-linker-steroidal (ALS) type platinum(II) pincer metallogelators. ${ }^{43}$ Very recently, Yi and coworkers designed and synthesized three alkynylplatinum(II) bipyridyl complexes with two cholesterol groups via alkyl chains and amido bonds, which can self-assemble to gel networks with a well-defined right-handed helical structure. ${ }^{44}$

In order to further investigate the effect of metal-metal (Pt $\cdots$ Pt) and $\pi-\pi$ stacking interactions in the self-assembly process of metallogels in organic solvents, herein, we designed and synthesized new type of binuclear alkynylplatinum(II) terpyridyl complexes with flexible bridges $\left(-\mathrm{O}\left(\mathrm{CH}_{2}\right)_{n} \mathrm{O}, n=4\right.$ or 6$)$, which were characterized by ${ }^{1} \mathrm{H}$ NMR, mass spectra and elemental analysis. The aromatic platinum(II) unit serves as chromophore, the long alkyl chains were selected as versatile gel-forming segments. Moreover, the amide groups, and binuclear platinum(II) complexes were readily introduced to examine the roles 
and extent of the metal-metal (Pt $\cdots \mathrm{Pt})$ and $\pi-\pi$ stacking interactions among the platinum(II) cores, the hydrogen bonding and the van der Waals forces among the amide groups and long alkyl chains as well. It is anticipated that with the cooperative multiple intermolecular interactions, such compounds can self-assemble into long fibers in organic solvents and entangle further to form gels. This expectation was found indeed to be the case. According to the different length of the flexible bridges, 1a can gel aromatic solvents such as benzene, toluene and aniline, while $\mathbf{1 b}$ can not only gel aromatic solvents such as benzene, toluene and aniline, but also gel other solvents such as butanol, pentanol, heptane, and 1,2-epoxypropane.

\section{Experimental}

\subsection{Materials}

Unless specifically mentioned, all chemicals are commercially available and were used as received. Triethylamine (TEA) were distilled over $\mathrm{CaH}_{2}$ under a nitrogen atmosphere prior to use. $4^{\prime}$ Chloro-2,2' $: 6^{\prime}, 2^{\prime \prime}$-terpyridine, ${ }^{45}$ dodecyloxy-terminal alkyne, ${ }^{46}$ compound $1,{ }^{23-27,35} 2$ (ref. 47) and 3 (ref. 23-27,35) were prepared according to the literature procedures.

\subsection{General method and instruments}

NMR spectra were obtained on a Bruker Avance 400 spectrometer (400 MHz $\left.{ }^{1} \mathrm{H} \mathrm{NMR}\right)$ at room temperature. Chemical shifts $(\delta)$ are reported in parts per million (ppm) using the solvent residual signal as an internal reference. Coupling constants $(J)$ are given in hertz. Each resonance multiplicity is described as $\mathrm{s}$ (singlet), d (doublet), t (triplet), q (quartet), dd (doublet of doublets), $\mathrm{m}$ (multiplet), or br (broad signal). Variabletemperature ${ }^{1} \mathrm{H}$ NMR experiments were carried out on Bruker DMX 300 spectrometer. Mass spectra (EI, ESI) were obtained in the positive ion mode on a Waters GCT Premier, Waters-QTOF and Bruker Daltonics Microflex spectrometer, respectively. Elemental analyses (CHN) were performed at FLASH EA1112 Elemental Analyzer. UV-vis spectra were obtained on a Shimadzu UV-1601PC spectrophotometer. The solvents for spectroscopic studies were of spectroscopic grade and used as received. Rheological properties were measured by a Thermo Haake RS300 rheometer with cone and plate geometry $(35 \mathrm{~mm}$ diameter, $0.105 \mathrm{~mm}$ cone gap). The frequency spectra were conducted in the linear viscoelastic regime of the samples determined from dynamic strain sweep measurements at $25{ }^{\circ} \mathrm{C}$. Fourier transform infrared (FT-IR) spectra of xerogels were measured at room temperature using a Varian Excalibur 3100 spectrometer. Xerogels were prepared by casting gels of toluene onto a $\mathrm{KBr}$ plate, and dried in the air. Field emission scanning electron microscopy (FESEM) images were obtained on a HITACHI S-4300 instrument operating at $10 \mathrm{kV}$ with $\mathrm{Au}$ coated. Samples for FESEM measurement were prepared by wiping a small amount of gel onto a silicon wafer followed by naturally evaporating the solvent. Gels in toluene were coated on a glass plate and the solvent was slowly evaporated at room temperature. Then the glass plates with dried gels were fixed on a sample holder and subjected to X-ray diffraction (XRD) analysis at room temperature on Bruker D8 Focus. XRD patterns were recorded at scanning rate of $2^{\circ} \mathrm{min}^{-1}$ in the $2 \theta$ range of $5^{\circ}$ to $60^{\circ}$ with $\mathrm{Cu}-\mathrm{K} \alpha$ radiation $(\lambda=1.54178 \AA)$.

\subsection{Synthesis and characterization}

Synthesis of compound 2. To a stirred suspension of powdered $\mathrm{KOH}(0.5 \mathrm{~g}, 8.93 \mathrm{mmol})$ in dry dimethyl sulfoxide (DMSO) $(20 \mathrm{~mL})$ at $80^{\circ} \mathrm{C}, 1,6$-hexanediol $(0.11 \mathrm{~g}, 0.93 \mathrm{mmol})$ or 1,4-butanediol ( $0.08 \mathrm{~g}, 0.89 \mathrm{mmol})$ was added. After $30 \mathrm{~min}, 4^{\prime}$ chloro-2, $2^{\prime}: 6^{\prime}, 2^{\prime \prime}$-terpyridine was added $(0.5 \mathrm{~g}, 1.87 \mathrm{mmol})$ and the mixture was stirred for $4 \mathrm{~h}$ at $60^{\circ} \mathrm{C}$ and then poured into 200 $\mathrm{mL}$ of distilled water. The aqueous phase was extracted with $\mathrm{CH}_{2} \mathrm{Cl}_{2}(3 \times 100 \mathrm{~mL})$. The combined organic phases were dried over $\mathrm{Na}_{2} \mathrm{SO}_{4}$ and evaporated in vacuo to dryness. The crude product was purified by silica gel flash column chromatography $\left(\mathrm{CH}_{2} \mathrm{Cl}_{2} / \mathrm{MeOH}, 2 / 1\right)$ to give 2 as a white solid.

2a. (0.48 g, $0.87 \mathrm{mmol}, 98 \%) .{ }^{1} \mathrm{H} \mathrm{NMR}\left(400 \mathrm{MHz} \mathrm{CDCl}_{3}\right) \delta 8.68$ $(\mathrm{d}, J=4.6 \mathrm{~Hz}, 4 \mathrm{H}), 8.60(\mathrm{~d}, J=7.9 \mathrm{~Hz}, 4 \mathrm{H}), 8.03(\mathrm{~s}, 4 \mathrm{H}), 7.84(\mathrm{~m}$, $4 \mathrm{H}), 7.32(\mathrm{dd}, J=7.3,4.9 \mathrm{~Hz}, 4 \mathrm{H}), 4.34(\mathrm{~s}, 4 \mathrm{H}), 2.10$ (s, 4H). EI-MS: $m / z$ calcd for $\mathrm{C}_{34} \mathrm{H}_{28} \mathrm{~N}_{6} \mathrm{O}_{2}: 552.2$, found: $553.2[\mathrm{M}+1]^{+}$.

2b. (0.53 g, $0.91 \mathrm{mmol}, 98 \%) .{ }^{1} \mathrm{H}$ NMR (400 $\mathrm{MHz}, \mathrm{CDCl}_{3}$ ) $\delta 8.70(\mathrm{~d}, J=3.7 \mathrm{~Hz}, 4 \mathrm{H}), 8.63(\mathrm{~d}, J=7.9 \mathrm{~Hz}, 4 \mathrm{H}), 8.05(\mathrm{~s}, 4 \mathrm{H})$, $7.87(\mathrm{t}, J=7.1 \mathrm{~Hz}, 4 \mathrm{H}), 7.40-7.30(\mathrm{~m}, 4 \mathrm{H}), 4.27(\mathrm{q}, J=6.5 \mathrm{~Hz}$, $4 \mathrm{H}), 2.03-1.78(\mathrm{~m}, 4 \mathrm{H}), 1.63(\mathrm{~d}, J=6.9 \mathrm{~Hz}, 4 \mathrm{H})$. EI-MS: $m / z$ calcd for $\mathrm{C}_{36} \mathrm{H}_{32} \mathrm{~N}_{6} \mathrm{O}_{2}$ : 580.26, found: $580.26[\mathrm{M}]^{+}$.

Synthesis of compound 3. A mixture of $2(200 \mathrm{mg}, 0.34$ $\mathrm{mmol}$ ) and $\mathrm{K}_{2} \mathrm{PtCl}_{4}(286 \mathrm{mg}, 0.69 \mathrm{mmol})$ in $\mathrm{H}_{2} \mathrm{O}(50 \mathrm{~mL})$ and $\mathrm{CH}_{3} \mathrm{CN}\left(50 \mathrm{~mL}\right.$ ) was stirred overnight at $80{ }^{\circ} \mathrm{C}$. After cooling to the room temperature, the product was filtered off and washed with water. Subsequent recrystallization by diffusion of diethyl ether vapor into a solution of the product in $\mathrm{CH}_{3} \mathrm{CN}$ gave 3 as a yellow green solid.

3a. (0.31 g, $0.28 \mathrm{mmol}, 78 \%) .{ }^{1} \mathrm{H}$ NMR (400 MHz, DMSO) $\delta 8.76$ $(\mathrm{d}, J=5.4 \mathrm{~Hz}, 4 \mathrm{H}), 8.41(\mathrm{~d}, J=7.8 \mathrm{~Hz}, 4 \mathrm{H}), 8.29(\mathrm{t}, J=7.6 \mathrm{~Hz}, 4 \mathrm{H})$, $8.16(\mathrm{~s}, 4 \mathrm{H}), 7.95-7.87(\mathrm{~m}, 4 \mathrm{H}), 4.61(\mathrm{~s}, 4 \mathrm{H}), 2.17$ (s, 4H). ESI-MS: $m / z$ calcd for $\left[\mathrm{C}_{34} \mathrm{H}_{28} \mathrm{Cl}_{2} \mathrm{~N}_{6} \mathrm{O}_{2} \mathrm{Pt}_{2}\right]^{2+}: 506.045$, found: 506.132 $[\mathrm{M}]^{2+}$. Elemental analysis: calcd $(\%)$ for $\mathrm{C}_{34} \mathrm{H}_{28} \mathrm{Cl}_{4} \mathrm{~N}_{6} \mathrm{O}_{2} \mathrm{Pt}_{2}: \mathrm{C}$, 37.65; H, 2.60; N, 7.75, found: C, 37.58; H, 2.68; N, 7.69.

3b. (0.29 g, $0.26 \mathrm{mmol}, 75 \%) .{ }^{1} \mathrm{H}$ NMR (300 MHz, DMSO) $\delta 8.27(\mathrm{t}, J=6.5 \mathrm{~Hz}, 8 \mathrm{H}), 8.13(\mathrm{dd}, J=15.7,7.8 \mathrm{~Hz}, 8 \mathrm{H}), 7.59(\mathrm{t}$, $J=6.3 \mathrm{~Hz}, 4 \mathrm{H}), 4.49(\mathrm{~s}, 4 \mathrm{H}), 1.89(\mathrm{~s}, 4 \mathrm{H}), 1.58$ (s, $4 \mathrm{H})$. ESI-MS: $m /$ $z$ calcd for $\left[\mathrm{C}_{36} \mathrm{H}_{32} \mathrm{Cl}_{2} \mathrm{~N}_{6} \mathrm{O}_{2} \mathrm{Pt}_{2}\right]^{2+}: 520.875$, found: $520.561[\mathrm{M}]^{2+}$. Elemental analysis: calcd (\%) for $\mathrm{C}_{36} \mathrm{H}_{32} \mathrm{Cl}_{4} \mathrm{~N}_{6} \mathrm{O}_{2} \mathrm{Pt}_{2}$ : C, 38.86; $\mathrm{H}$, 2.90 ; N, 7.55, found: C, 38.97; H, 2.95; N, 7.62.

General synthetic procedures for $1 \mathrm{a}$ and $1 \mathrm{~b}$. A mixture of dodecyloxy-terminal alkyne (300 mg, $0.36 \mathrm{mmol}), 3$ (200 mg, $0.18 \mathrm{mmol}$ ), CuI (10 mg), dimethylformamide (DMF) (3 mL) and triethylamine (TEA) $(6 \mathrm{~mL})$ was sonicated under nitrogen for $8 \mathrm{~h}$. Thereafter, excess diethyl ether was added into the mixture and the product was filtered off and washed with water and diethyl ether. Subsequent recrystallisation by diffusion of diethyl ether vapour into a solution of the product in acetonitrile gave 1 as a brown red solid.

1a. (0.31 g, $0.11 \mathrm{mmol}, 62 \%) .{ }^{1} \mathrm{H}$ NMR (400 MHz, Pyr) $\delta 9.31$ $(\mathrm{d}, J=15.2 \mathrm{~Hz}, 4 \mathrm{H}), 8.70(\mathrm{~s}, 8 \mathrm{H}), 8.21(\mathrm{~d}, J=8.2 \mathrm{~Hz}, 4 \mathrm{H})$, 
$7.72(\mathrm{~s}, 4 \mathrm{H}), 7.63(\mathrm{~d}, J=8.1 \mathrm{~Hz}, 4 \mathrm{H}), 7.15(\mathrm{~s}, 8 \mathrm{H}), 4.99(\mathrm{~s}, 16 \mathrm{H})$, $4.24(\mathrm{t}, J=6.3 \mathrm{~Hz}, 4 \mathrm{H}), 3.94(\mathrm{t}, J=6.2 \mathrm{~Hz}, 8 \mathrm{H}), 3.73(\mathrm{~d}, J=5.4 \mathrm{~Hz}$, $8 \mathrm{H}), 2.07-1.81(\mathrm{~m}, 8 \mathrm{H}), 1.70(\mathrm{dd}, J=31.9,24.3 \mathrm{~Hz}, 12 \mathrm{H}), 1.50-$ $0.94(\mathrm{~m}, 96 \mathrm{H}), 0.81(\mathrm{t}, J=6.6 \mathrm{~Hz}, 18 \mathrm{H})$. ESI-MS: $\mathrm{m} / \mathrm{z}$ calcd for $\left[\mathrm{C}_{144} \mathrm{H}_{206} \mathrm{~N}_{10} \mathrm{O}_{12} \mathrm{Pt}_{2}\right]^{2+}: 2657.51$, found: $2657.75[\mathrm{M}]^{2+}$. Elemental analysis: calcd (\%) for $\mathrm{C}_{34} \mathrm{H}_{28} \mathrm{Cl}_{2} \mathrm{~N}_{6} \mathrm{O}_{2} \mathrm{Pt}_{2}$ : C, 63.65; $\mathrm{H}, 7.60 ; \mathrm{N}$, 5.13, found: C, 63.51; H, 7.65; N, 5.18.

1b. (0.33 g, $0.12 \mathrm{mmol}, 66 \%) .{ }^{1} \mathrm{H} \mathrm{NMR} \mathrm{(400} \mathrm{MHz,} \mathrm{Pyr)} \delta 9.31$ $(\mathrm{s}, 4 \mathrm{H}), 8.68(\mathrm{~s}, 8 \mathrm{H}), 8.22(\mathrm{~s}, 4 \mathrm{H}), 7.69(\mathrm{~d}, J=31.6 \mathrm{~Hz}, 8 \mathrm{H}), 7.15(\mathrm{~s}$, $8 \mathrm{H}), 4.94(\mathrm{~s}, 16 \mathrm{H}), 4.25(\mathrm{~s}, 4 \mathrm{H}), 3.96(\mathrm{~s}, 8 \mathrm{H}), 3.75(\mathrm{~s}, 8 \mathrm{H}), 1.94$ (d, $J=27.6 \mathrm{~Hz}, 8 \mathrm{H}), 1.69$ (d, $J=48.5 \mathrm{~Hz}, 12 \mathrm{H}), 1.32$ (d, $J=$ $75.1 \mathrm{~Hz}, 100 \mathrm{H}), 0.94-0.59(\mathrm{~m}, 18 \mathrm{H})$. ESI-MS: $\mathrm{m} / \mathrm{z}$ calcd for $\left[\mathrm{C}_{146} \mathrm{H}_{210} \mathrm{~N}_{10} \mathrm{O}_{12} \mathrm{Pt}_{2}\right]^{2+}: 2687.55$, found: $2687.63[\mathrm{M}]^{2+}$. Elemental analysis: calcd (\%) for $\mathrm{C}_{146} \mathrm{H}_{210} \mathrm{Cl}_{2} \mathrm{~N}_{10} \mathrm{O}_{12} \mathrm{Pt}_{2}$ : C, 65.25; H, 7.88; N, 5.21, found: C, 65.37; H, 7.80; N, 5.26.

\subsection{Gelation test}

The formation of metallogels was evaluated using a tube inversion method. A weighed amount of the compound in a selected solvent $(0.5 \mathrm{~mL})$ was placed in a glass vial, which was sealed and heated until the compound was dissolved. After the solution was allowed to stand at room temperature for about $12 \mathrm{~h}$, the state of the solution was examined by the "stable to inversion of a test tube" method. The reversibility of the gelation was confirmed by repeated heating and cooling. The critical gelation concentration (CGC) was determined from the minimum amount of gelator required for the formation of gel at room temperature. All experiments for CGC-determinations were run three times for reliable data.

If no flow was observed when inverting the vial, a stable gel was formed and noted as gelation (G). If part of the mixture formed a gel but flow was still observed, the phenomenon was recorded as partial gel (PG). If precipitation occurred, P was noted, and if the clear solution was retained, it was marked as soluble (S). If the compound was unable to dissolve, it was noted as insoluble (I).

\section{Results and discussion}

The synthesis of new gelators based on platinum(II) complexes 1a and $\mathbf{1 b}$ were accomplished in high yields by using the Sonogashira reaction (Scheme 1). The starting compound $4^{\prime}$ chloro-2,2': $6^{\prime}, 2^{\prime \prime}$-terpyridine was directly reacted with 1,6-hexanediol $(0.11 \mathrm{~g}, 0.93 \mathrm{mmol})$ or 1,4-butanediol with the aid of $\mathrm{KOH}$ in DMSO, to give 2a and $2 \mathbf{b}$. After refluxing with $\mathrm{K}_{2} \mathrm{PtCl}_{4}$ in the mixture solvents of acetonitrile and water, $\mathbf{3 a}$ and $\mathbf{3 b}$ were obtained through recrystallization by diffusion of diethyl ether vapor into a solution of the product in acetonitrile. Then $\mathbf{3 a}$ and 3b were reacted with dodecyloxy-terminal alkyne in the presence of TEA in DMF under typical Sonogashira reaction conditions to produce target compounds $\mathbf{1 a}$ and $\mathbf{1 b}$, which were identified by ${ }^{1} \mathrm{H}$ NMR, electrospray ionization mass spectrometry (ESI MS), and satisfactory elemental analysis.

As shown in Fig. 1, the UV-vis absorption spectra of $\mathbf{1 a}$ and $\mathbf{1 b}$ in DMSO showed a typical metal-to-ligand charge transfer (MLCT) $\left[\mathrm{d} \pi(\mathrm{Pt})-\pi^{*}\right.$ (terpy)] band with a maximum at $475 \mathrm{~nm}$ and

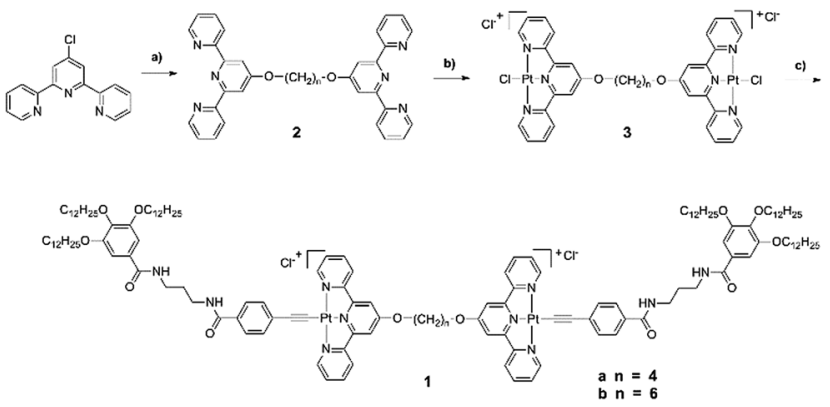

Scheme 1 Chemical structures and synthesis routes of 1 . $^{a}$ (a) 1,6Hexanediol or 1,4-butanediol, DMSO, $\mathrm{KOH}$; (b) $\mathrm{K}_{2} \mathrm{PtCl}_{4}, \mathrm{CH}_{3} \mathrm{CN}, \mathrm{H}_{2} \mathrm{O}$; (c) dodecyloxy-terminal alkyne, Cul, DMF, TEA.

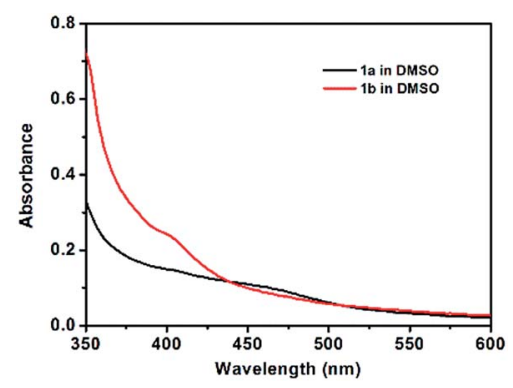

Fig. 1 UV-vis absorption spectral changes of compound 1a $(2.20 \times$ $\left.10^{-5} \mathrm{M}\right)$ and $1 \mathrm{~b}\left(2.18 \times 10^{-5} \mathrm{M}\right)$ in DMSO at room temperature.

$450 \mathrm{~nm}$ mixed with an ligand-to-ligand charge transfer (LLCT) $\left[\pi(\mathrm{C} \equiv \mathrm{C})-\pi^{*}(\mathrm{tpy})\right]$ transition, respectively. The weak electronic absorption from 500-550 $\mathrm{nm}$ probably originates from metalmetal-to-ligand charge transfer (MMLCT) $\left[\left(\mathrm{d} \sigma^{*}-\pi^{*}\right)\right]$ transition as a result of the possible existence of intermolecular metalmetal and $\pi-\pi$ interactions in DMSO solution, which indicates the aggregation of the molecules. The concentration-dependent UV-vis absorption spectral changes as shown in Fig. S1 $\uparrow$ further demonstrated the aggregation of the molecules with increase of the concentration of $\mathbf{1 a}$ and $\mathbf{1 b}$ in DMSO solution through the enhancement of the absorption band from 500 to $550 \mathrm{~nm}$. Both 1a and $\mathbf{1 b}$ have no emission in DMSO solution at room temperature. This could possibly be ascribed to intramolecular reductive electron-transfer quenching of the ${ }^{3}$ MLCT state as well as energy transfer to the low-lying ${ }^{3}$ LLCT state arising from the presence of the electron-rich alkoxy groups on the phenyl ligand. ${ }^{\mathbf{1 6}}$

In order to further confirm the formation of gels, the rheological measurements of $\mathbf{1 a}$ and $\mathbf{1 b}$ in toluene were carried out as shown in Fig. 2. Both the samples of gel $\mathbf{1 a}$ and gel $\mathbf{1} \mathbf{b}$ in toluene were deformed sinusoidally with frequency $f$ to give the elastic modulus $\left(\mathrm{G}^{\prime}\right)$ and viscous modulus $\left(\mathrm{G}^{\prime \prime}\right)$. Meanwhile, the $\mathrm{G}^{\prime}$ values of the samples were basically invariant with the frequencies, and the $G^{\prime}$ values exceeded $G^{\prime \prime}$ values over the entire range of frequencies in samples of gel $\mathbf{1 a}$ and gel $\mathbf{1 b}$.

The gelation ability of compound $\mathbf{1 a}$ and $\mathbf{1 b}$ was examined in various solvents by means of the "stable to inversion of a test tube" method. The corresponding critical gelation concentrations (CGC) at room temperature were also measured. As shown 

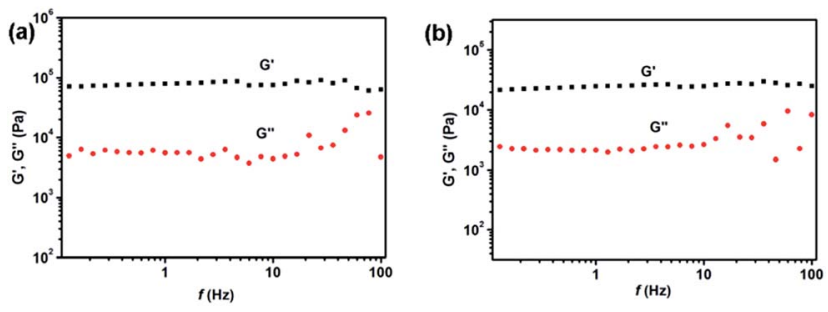

Fig. 2 Rheological properties of $1 \mathrm{a}\left(23 \mathrm{mg} \mathrm{mL}^{-1}\right)$ and $1 \mathrm{~b}\left(20 \mathrm{mg} \mathrm{mL}^{-1}\right)$ in toluene.

in Table 1 and Fig. 3, compound 1a can gel aromatic solvents such as benzene, toluene and aniline; while compound $\mathbf{1 b}$ can not only gel aromatic solvents but also butanol, petanol, 1,2epoxypropane and heptane through the extension of the flexible bridges. These gels were found to be stable in closed tubes for at least 3 months at $25{ }^{\circ} \mathrm{C}$. The better gelation for aromatic solvents relative to the hydrocarbon or halogenated hydrocarbons is probably due to the enhancement of $\pi-\pi$ interactions in aromatic solvents. ${ }^{3}$

The morphology of xerogels obtained from different solvents was characterized by field emission scanning electron microscopy (FESEM) by evaporating the solvent at ambient under identical conditions. For 1a in benzene, due to the serious fusion of the fibers during the evaporation of the solvent, there is no obvious fibrous structures even under high magnification (Fig. 4b and c). In the case of aniline, the xerogels exhibited a closely packed three-dimensional (3D) network structure, which was composed of uniform fibers with diameter about $60 \mathrm{~nm}$ extending over micrometers (Fig. 4d and e). As for toluene for 1a, a similar fibrous structures consisted of highly entangled fibers was also observed (Fig. 4f and g). In 1,2-epoxypropane for $\mathbf{1 b}$, a loose packed network composed of long and thick fibers about $100 \mathrm{~nm}$ in diameter and even over several micrometers in length were observed (Fig. 5b and c). The xerogels of $\mathbf{1 b}$ from butanol were consisted of highly entangled fibers, which were much thinner and longer with some fusion (Fig. 5d and e). In contrast, the xerogels derived from aromatic solvents such as benzene, aniline and toluene exhibited serious fusion of the fibers only under high magnification (Fig. $5 \mathrm{f}-\mathrm{i}$ ).

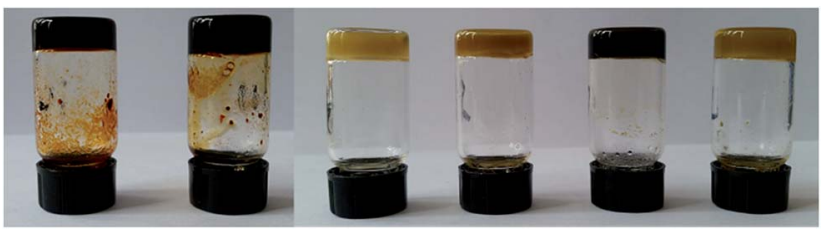

Fig. 3 Selected metallogels of $1 \mathrm{a}$ in toluene and aniline; and $1 \mathrm{~b}$ in heptane, benzene, aniline and toluene (from left to right).
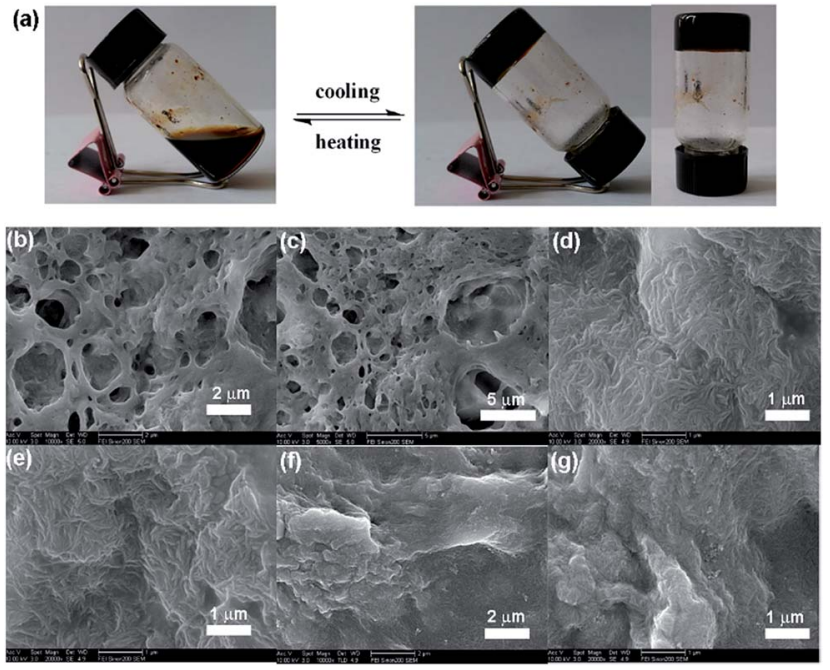

Fig. 4 Phase transition behavior of the sol (left) and gel (right) phases of 1a (a) in aniline; and FESEM image of xerogels of $1 \mathrm{a}$ in different solvents: (b, c) benzene, $(d, e)$ aniline, $(f, g)$ toluene. Samples were prepared by drop-casting the gels on a silicon substrate, drying under air, and coating with $\mathrm{Au}$.

The xerogels of $\mathbf{1 b}$ in heptane showed tightly packed and much thicker fibers (Fig. $5 \mathrm{l}$ and $\mathrm{m}$ ).

The intermolecular hydrogen bonding between the amide groups was investigated by Fourier transform infrared (FT-IR) spectroscopy, which is an important tool for studying the different non-covalent interactions involved in gelation. As shown in Fig. 6a and b, compared to the non-hydrogen-bonding transmittance band of $\mathbf{1 a}$ and $\mathbf{1 b}$ in chloroform solution at

Table 1 Gelation properties of $1 \mathrm{a}$ and $1 \mathrm{~b}$ in selected organic solvents at room temperature $\mathrm{a}^{a, b}$

\begin{tabular}{|c|c|c|c|c|c|}
\hline Solvents & $1 \mathrm{a}$ & $1 \mathbf{b}$ & Solvents & $1 \mathrm{a}$ & $1 b$ \\
\hline Methanol & I & I & Acetonitrile & I & I \\
\hline Ethanol & I & I & Tetrahydrofuran & $\mathrm{P}$ & $\mathrm{P}$ \\
\hline Pentanol & PG & G (19.8) & Cyclohexane & I & I \\
\hline Petroleumether & PG & PG & 1,2-Epoxypropane & PG & $\mathrm{G}(23.6)$ \\
\hline Ethyl acetate & I & I & Benzene & $\mathrm{G}(26.9)$ & $\mathrm{G}(23.6)$ \\
\hline Dimethyl sulfoxide & PG & PG & Chloroform & I & I \\
\hline
\end{tabular}

${ }^{a}$ G: gel; PG: partial gel; P: precipitation; S: soluble; I: insoluble when heated. ${ }^{b}$ The critical gelation concentrations [CGC, mg mL ${ }^{-1}$ ] of gelators are shown in the parentheses. 


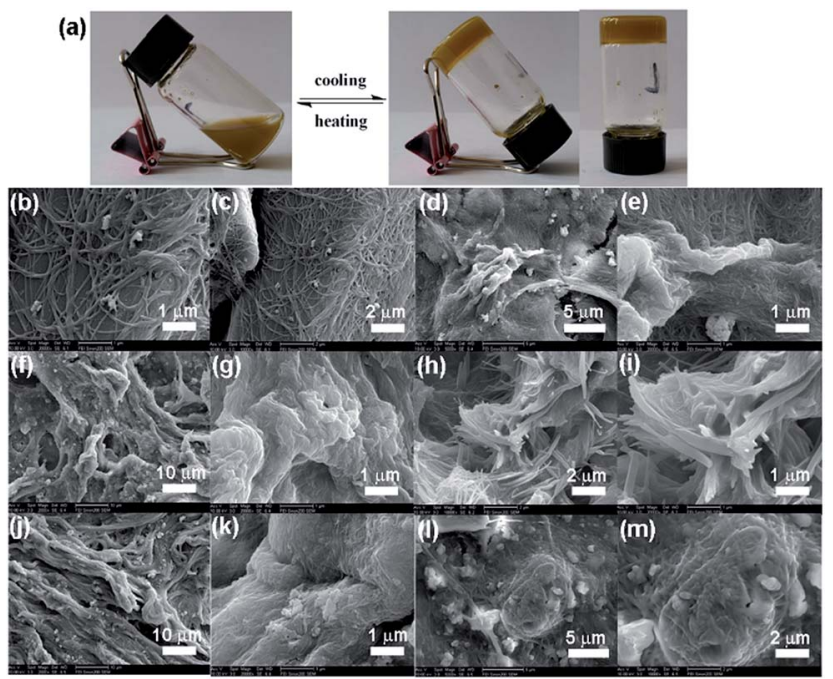

Fig. 5 Phase transition behavior of the sol (left) and gel (right) phases of $1 \mathrm{~b}(\mathrm{a})$ in toluene; and FESEM image of xerogels of $1 \mathrm{~b}$ in different solvents: (b, c) 1,2-epoxypropane, (d, e) butanol, (f, g) benzene, (h, i) aniline, $(\mathrm{j}, \mathrm{k})$ toluene, $(\mathrm{l}, \mathrm{m})$ heptane. Samples were prepared by dropcasting the gels on a silicon substrate, drying under air, and coating with $\mathrm{Au}$.
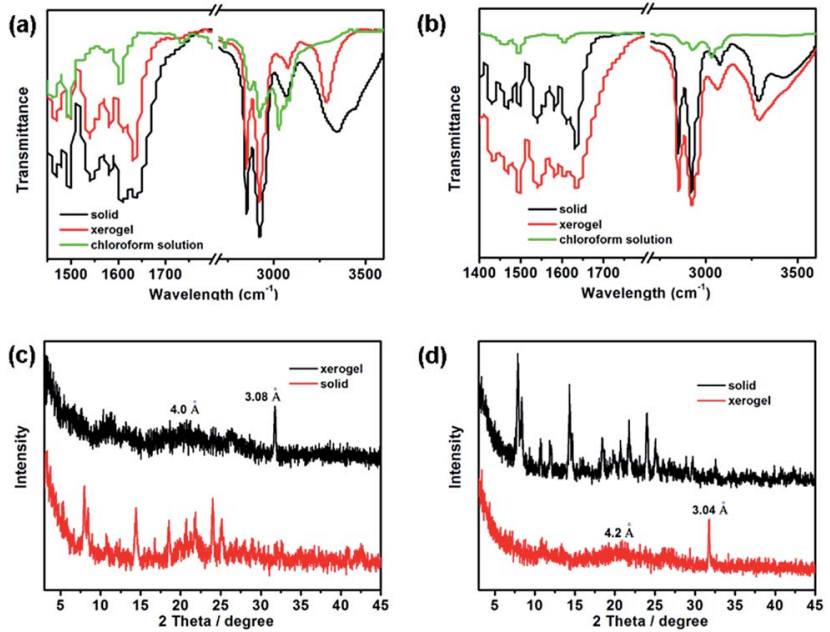

Fig. 6 The FT-IR spectra 1a (a) and 1b (b) in solid, xerogel (obtained from toluene) and chloroform solution; and XRD pattern of $1 \mathrm{a}$ (c) and $1 \mathrm{~b}(\mathrm{~d})$ in solid and xerogel (obtained from toluene).

3420-3390 $\mathrm{cm}^{-1}$ for $v_{\mathrm{N}-\mathrm{H}}$, a remarkable shift of the urea $\mathrm{N}-\mathrm{H}$ stretching vibration to a lower wavenumber around $3250 \mathrm{~cm}^{-1}$ was observed in xerogels $\mathbf{1 a}$ and $\mathbf{1 b . 4 8 9}$ Meanwhile, the absorption bands of the asymmetric $\left(v_{\text {asym }}\right)$ and symmetric $\left(v_{\text {sym }}\right) \mathrm{CH}_{2}$ stretching vibrations of xerogels of $\mathbf{1 a}$ and $\mathbf{1 b}$ were observed at 2922 and $2854 \mathrm{~cm}^{-1}$, which appear at a lower frequency, indicating a strong interaction between the alkyl chains (van der Waals interaction). ${ }^{38}$ Additionally, the $\mathrm{C}=\mathrm{O}$ stretching $\left(v_{\mathrm{C}=\mathrm{O}}\right)$ and $\mathrm{N}-\mathrm{H}$ bending $\left(\delta_{\mathrm{N}-\mathrm{H}}\right)$ bands for the xerogels respectively shifted to lower wavenumber at $1690 \mathrm{~cm}^{-1}$ and higher wavenumber at $1560 \mathrm{~cm}^{-1}$ which further confirmed the existence of hydrogen-bonding in the gel state. ${ }^{36,37}$
To probe the roles of the terpyridyl platinum(II) units as well as van der Waals interaction between alkyl chains in the gelation process, the X-rays diffractions (XRD) of the xerogels $1 \mathrm{a}$ and 1b obtained from toluene was estimated (Fig. 6c and d). The broad reflection peaks at $\sim 4.0 \AA$ for $1 \mathrm{a}$ and $\sim 4.2 \AA$ for $1 \mathrm{~b}$ are related to the $\pi-\pi$ stacking distance between the part of terpyridyl platinum(II) complexes. Moreover, the acute peaks at $\sim 3.08 \AA$ for $1 \mathrm{a}$ and $\sim 3.04 \AA$ for $\mathbf{1 b}$ are assigned to the metalmetal (Pt $\cdots \mathrm{Pt})$ and $\pi-\pi$ stacking interactions of the terpyridyl platinum(II) complexes., ${ }^{\mathbf{9 5 0}, 51}$ On the basis of FT-IR and XRD studies, it is clear that the cooperative interactions of the metalmetal (Pt $\cdots \mathrm{Pt}$ ) and $\pi-\pi$ stacking interactions of the terpyridyl platinum(II) complexes, the hydrogen bonding and the van de Waals forces among the amide groups and long alkyl chains can self-assemble molecules of $\mathbf{1 a}$ and $\mathbf{1 b}$ into long fibers in organic solvents and entangle further to form gels. Meanwhile, the temperature-dependent ${ }^{1} \mathrm{H}$ NMR spectra of $\mathbf{1 a}$ and $\mathbf{1 b}$ are also carried out as shown in Fig. S2. $\dagger$ With temperature increasing to $80{ }^{\circ} \mathrm{C}$ by $10{ }^{\circ} \mathrm{C}$ steps, all of the signals in the ${ }^{1} \mathrm{H}$ NMR spectra became sharp and strong, along with the notable splitting, which further indicate the existence of non-covalent interactions between molecules.

\section{Conclusions}

In summary, we have designed and synthesized new type of binuclear alkynylplatinum(II) terpyridyl complexes bridged by flexible chains $\left(-\mathrm{O}\left(\mathrm{CH}_{2}\right)_{n} \mathrm{O}-, n=4\right.$ or 6$)$. Benefiting from the metal-metal (Pt $\cdots \mathrm{Pt})$ and $\pi-\pi$ stacking interactions of platinum(II) complexes, hydrogen bonding interactions of amide groups, and van der Waals forces of the long alkyl chains, 1a and 1b can form stable metallogels through the entanglement of fibrous aggregates in several organic solvents. Moreover, the extension of the flexible bridges has obvious effect to the formation of the metallogels. The longer of the chain length, the more solvents to form metallogels. The experimental study presented herein could have important potentials for the fabrication of metallogels based on platinum(II) complexes with the aid of the cooperative multiple intermolecular interactions.

\section{Acknowledgements}

We are grateful for the financial support from the National Natural Science Foundation of China (21402108), Shandong Natural Science Foundation (ZR2014BQ036), and the China Postdoctoral Science Foundation (2016M590630).

\section{Notes and references}

1 A. Ajayaghosh and S. George, J. Am. Chem. Soc., 2001, 123, 5148-5149.

2 P. Dastidar, Chem. Soc. Rev., 2008, 37, 2699-2715.

3 M. George and R. G. Weiss, Acc. Chem. Res., 2006, 39, 489497.

4 Z. Yang, G. Liang and B. Xu, Acc. Chem. Res., 2008, 41, 315326. 
5 N. Sangeetha and U. Maitra, Chem. Soc. Rev., 2005, 34, 821836.

6 S. S. Babu, V. K. Praveen and A. Ajayaghosh, Chem. Rev., 2014, 114, 1973-2129.

7 S. Banerjee, R. Das and U. Maitra, J. Mater. Chem., 2009, 19, 6649-6687.

8 A. Ajayaghosh, V. K. Praveen and C. Vijayakumar, Chem. Soc. Rev., 2008, 37, 109-122.

9 X. Chen, Z. Huang, S.-Y. Chen, K. Li, X.-Q. Yu and L. Pu, J. Am. Chem. Soc., 2010, 132, 7297-7299.

10 W. Weng, J. B. Beck, A. M. Jamieson and S. J. Rowan, J. Am. Chem. Soc., 2006, 128, 11663-11672.

11 S. Bhowmik, B. N. Ghosh, V. Marjomäki and K. Rissanen, J. Am. Chem. Soc., 2014, 136, 5543-5546.

12 L. Sambri, F. Cucinotta, G. D. Paoli, S. Stagni and L. D. Cola, New J. Chem., 2010, 34, 2093-2096.

13 J. Zhang and C.-Y. Su, Coord. Chem. Rev., 2013, 257, 13731408.

14 J. Wang, Y. Chen, Y. C. Law, M. Li, M. X. Zhu, W. Lu, S. S. Y. Chui, N. Zhu and C. M. Che, Chem.-Asian J., 2011, 6, 3011-3019.

15 H. X. Zhang, M. Kato, Y. Sasaki, T. Ohba, H. Ito, A. Kobayashi, H. C. Chang and K. Uosaki, Dalton Trans., 2012, 41, 11497-11506.

16 A. Y. Y. Tam, K. M. C. Wong, N. Zhu, G. Wang and V. W. W. Yam, Langmuir, 2009, 25, 8685-8695.

17 C. Po, Z. Ke, A. Y.-Y. Tam, H.-F. Chow and V. W.-W. Yam, Chem.-Eur. J., 2013, 19, 15735-15744.

18 A. Y. Y. Tam, K. M. C. Wong and V. W. W. Yam, Chem.-Eur. J., 2009, 15, 4775-4778.

19 V. H. Houlding and V. M. Miskowski, Coord. Chem. Rev., 1991, 111, 145-152.

20 D. R. McMillin and J. J. Moore, Coord. Chem. Rev., 2002, 229, 113-121.

21 S.-W. Lai and C.-M. Che, Top. Curr. Chem., 2004, 241, 27-63.

22 I. Eryazici, C. N. Moorefield and G. R. Newkome, Chem. Rev., 2008, 108, 1834-1895.

23 D. Zhang, L. Z. Wu, L. Zhou, X. Han, Q. Z. Yang, L. P. Zhang and C. H. Tung, J. Am. Chem. Soc., 2004, 126, 3440-3441.

24 X. Han, L. Z. Wu, G. Si, J. Pan, Q. Z. Yang, L. P. Zhang and C. H. Tung, Chem.-Eur. J., 2007, 13, 1231-1239.

25 Q. Z. Yang, L. Z. Wu, H. Zhang, B. Chen, Z. X. Wu, L. P. Zhang and C. H. Tung, Inorg. Chem., 2004, 43, 5195-5197.

26 J. Ding, K. Feng, C.-H. Tung and L.-Z. Wu, J. Phys. Chem. C, 2010, 115, 833-839.

27 X. Y. Liu, X. Han, L. P. Zhang, C. H. Tung and L. Z. Wu, Phys. Chem. Chem. Phys., 2010, 12, 13026-13033.

28 P. Du, J. Schneider, P. Jarosz and R. Eisenberg, J. Am. Chem. Soc., 2006, 128, 7726-7727.

29 W. Lu, B. X. Mi, M. C. W. Chan, Z. Hui, C. M. Che, N. Zhu and S. T. Lee, J. Am. Chem. Soc., 2004, 126, 4958-4971.
30 J. Thaddeus, Q. M. Wang, Y. Kim, C. Flaschenreim, T. N. Blanton and R. Eisenberg, J. Am. Chem. Soc., 2004, 126, 16841-16849.

31 K. M.-C. Wong and V. W.-W. Yam, Acc. Chem. Res., 2011, 44, 424-434.

32 W. Lu, V. Roy and C. M. Che, Chem. Commun., 2006, 39723974.

33 Y. Chen, K. Li, W. Lu, S. S. Y. Chui, C. W. Ma and C. M. Che, Angew. Chem., Int. Ed., 2009, 48, 9909-9913.

34 C. Po, A. Y.-Y. Tam, K. M.-C. Wong and V. W.-W. Yam, J. Am. Chem. Soc., 2011, 133, 12136-12143.

35 L.-B. Xing, S. Yu, X.-J. Wang, G.-X. Wang, B. Chen, L.-P. Zhang, C.-H. Tung and L.-Z. Wu, Chem. Commun., 2012, 48, 10886-10888.

36 N. Liu, B. Wang, W. Liu and W. Bu, Chem. Commun., 2011, 47, 9336-9338.

37 A. Y.-Y. Tam, K. M.-C. Wong, G. Wang and V. W.-W. Yam, Chem. Commun., 2007, 2028-2030.

38 F. Camerel, R. Ziessel, B. Donnio, C. Bourgogne, D. Guillon, M. Schmutz, C. Iacovita and J.-P. Bucher, Angew. Chem., Int. Ed., 2007, 46, 2659-2662.

39 W. Lu, Y. C. Law, J. Han, S. S. Y. Chui, D. L. Ma, N. Zhu and C. M. Che, Chem.-Asian J., 2008, 3, 59-69.

40 A. Y.-Y. Tam, K. M.-C. Wong and V. W.-W. Yam, J. Am. Chem. Soc., 2009, 131, 6253-6260.

41 C. A. Strassert, C.-H. Chien, M. D. Galvez Lopez, D. Kourkoulos, D. Hertel, K. Meerholz and L. De Cola, Angew. Chem., Int. Ed., 2011, 50, 946-950.

42 L. De Cola, N. K. Allampally and C. Strassert, Dalton Trans., 2012, 41, 13132-13137.

43 T. Tu, W. Fang, X. Bao, X. Li and K. H. Dötz, Angew. Chem., Int. Ed., 2011, 50, 6601-6605.

44 Y. Mao, K. Liu, L. Meng, L. Chen, L. Chen and T. Yi, Soft Matter, 2014, 10, 7615-7622.

45 E. C. Constable and M. D. Ward, J. Chem. Soc., Dalton Trans., 1990, 1405-1409.

46 X.-J. Wang, L.-B. Xing, W.-N. Cao, X.-B. Li, B. Chen, C.-H. Tung and L.-Z. Wu, Langmuir, 2011, 27, 774-781.

47 U. S. Schubert, C. Eschbaumer, O. Hien and P. R. Andres, Tetrahedron Lett., 2001, 42, 4705-4707.

48 J. Puigmartí-Luis, A. Minoia, P. del Pino, G. Ujaque, C. Rovira, A. Ledós, R. Lazzaroni and D. Amabilino, Chem.Eur. J., 2006, 12, 9161-9175.

49 J. Puigmartí-Luis, Á. Pérez del Pino, E. Laukhina, J. Esquena, V. Laukhin, C. Rovira, J. Vidal-Gancedo, A. G. Kanaras, R. J. Nichols, M. Brust and D. B. Amabilino, Angew. Chem., Int. Ed., 2008, 47, 1861-1865.

50 B. Mohr, G. Wegner and K. Ohta, J. Chem. Soc., Chem. Commun., 1995, 995-996.

51 J. Wang, Y. Chen, Y. C. Law, M. Li, M. X. Zhu, W. Lu, S. S. Y. Chui, N. Zhu and C. M. Che, Chem.-Asian J., 2011, 6, 3011-3019. 